\title{
Quality Assessment of Dry Fishes of Bangladesh with the Special Emphasis on Harmful Additives
}

\section{Nurul Huda Bhuiyana*, Mamtaz Dawlatana a, Habibur Rahman Bhuiyan', Farhana Akter Lucky', Barun Kanti Saha ${ }^{a}$ and M. Nazrul Islam Bhuiyan ${ }^{b}$}

\author{
${ }^{a} I F S T$, BCSIR, Dhaka, Bangladesh. ${ }^{b}$ BCSIR Laboratories, Chittagong Cantonment, Chittagong-4220, \\ Bangladesh, and ${ }^{C}$ Department of Biochemistry \& Molecular Biology, University of Dhaka.
}

\begin{abstract}
Proximate biochemical analysis and screening of organochlorine insecticides (Heptachlor and DDT) of six dry fish samples namely Bombay duck (Loittya), Ribbon fish (Chhuri), Anchovy (Teilla phasa), Croaker (Poa), Chinese pomfret (Rupchanda) and Indian salmon (Lakhua) were analyzed to assess the quality of dry fishes of Bangladesh. The fish samples were concentrated source of protein (minimum $42.50 \%$ in Indian salmon to maximum 64.51\% in Ribbon fish) and ash (mineral) (minimum $0.21 \%$ in Indian salmon to maximum 6.44\% in Croaker fish). Organochlorine insecticides (DDT and Heptachlor) were found in all the samples of dry fish analyzed. The minimum concentration of Heptachlor and DDT were found in Ribbon fish (0.778 ppb) and in Chinese pomfret (7.849 ppb) respectively and the maximum concentration of Heptachlor and DDT were found in Chinese pomfret (54.753 ppb) and in Indian salmon 233.727 ppb respectively.
\end{abstract}

Key words: Dry fish, Concentration, Organochlorine insecticides, DDT, Heptachlor, Proximate analysis.

\section{Introduction}

Fish is a valuable and easily accessible source of protein (Bhuiyan, et. al., 2004). Among the fish product dry fish (Locally named as Shutki) is the most popular food items in Bangladesh. It is a concentrated source of protein and mineral and can combat against protein malnutrition. The coastal areas, rivers and several haors are famous for producing dry fish, which is dried under the sun from mid October to mid April. Huge amount of fish are generally caught from fresh and marine water during winter season. During this time the Bay of Bengal, the coastal crisscross channels and other depressions remain calm and quiet and as a result fishing activities are strengthened and huge fishes are harvested during this period than the other seasons. The necessity to cultivate dry fish looms up when huge quantity of fresh fish caught everyday remains unsold because of shortage of customers and cannot be sent to the towns or the metropolis on a daily basis either for shortage of transport or fish traders not willing to pay the right amount of money. As a result winter is considered to be the peak season for drying fish.

The finally dried fish products are generally stored in a dump warehouse either at the site or nearby coastal towns. Most unexpected cause of infestation is that the fishermen do not dry fishes properly preferably they do this for high cost fish

\footnotetext{
* Corresponding author: E-mail: nhbmb@yahoo.com
}

es such as Chinese pomfret and Indian salmon due to loss of weight i.e., the fishermen want more profit selling the dry fishes in weight. In addition to this, the weather is humid particularly during the monsoon period. The dry fishes absorbed moisture so rapidly that the fish becomes suitable for infestation by beetles and mites. For protection of dry fish from infestation they use insecticides whatever they are getting within their reach. These insecticides are health hazard both for users and consumers. There are many insecticides sold in the markets without names and insecticides are not true to the label. Unknown diluted varieties rarely contain any instructions on heath hazards are sold to unaware users. Nobody can draw a statistic on insecticide causalities, although newspapers reports on deaths and sufferings or chronic effects are common in Bangladesh. DDT (dichlorodiphenyltrichloroethane) and Heptachlor are banned in Bangladesh but there is no statistical figure about these organochlorine insecticides (UNEP, 2002). The Department of Environment, a member of Pesticide Technical Advisory Committee (PTAC) controls the pesticide registration scheme in Bangladesh. No pesticides and insecticides are registered without reviewing the available Toxicological and Eco-toxicological information of the pes- 
ticide. However, there is no specific legislation for controlling the production and use of hazardous industrial chemicals (UNEP, 2002).

The organochlorine insecticides are extremely lipophilic in nature and resistance to biodegradation, which results in their accumulation and concentration in fatty tissues and their extreme persistence in environment (Tannenbaum, 1979). Among the insecticides DDT is a commercial organochlorine insecticide that has been widely used on agricultural crops as well as for vector control (ATSDR, 1995). It was banned for all uses in 49 countries and restricted to vector control in 23 (PANNA, 1995). The half-life of DDT in humans is approximately 4 years (Noren and Meironyte, 2000). Heptachlor is another organochlorine cyclodiene pesticide that has been used to control termites and as an insecticide on seed grains and food crops. Heptachlor epoxide, the main metabolite of heptachlor, is extremely persistent in soil and have been found in soil 14-16 years after application (Extoxnet, 1996). Plants can draw heptachlor epoxide directly from the soil, and the chemical bioaccumulates in animals. It has been banned or restricted in more than 60 countries (WHO, 1988). However, some of these countries still permit its use for termite and other pest control, and many developing nations still use for agricultural purposes (Noronha, 1998). A study showed that countries have restricted and banned heptachlor; levels detected in breast milk have dropped, often by more than 10-fold (Jensen and Slorach, 1991). The objective of this study was to determine the quality of dry fish with the special emphasis on the screening of harmful and health hazard organochlorine insecticides like Heptachlor and DDT present in dry fish.

\section{Materials and Method}

Sampling: Six most popular dry fish samples namely Bombay duck (Loittya), Ribbon fish (Chhuri), Anchovy (Teilla phasa), Croaker (Poa), Chinese pomfret (Rupchanda) and Indian salmon (Lakhua) were collected from Karwan Bazaar of Dhaka (a whole sale market), Bangladesh for proximate biochemical analysis and screening of harmful additives.

The control samples (for screening of harmful additives) of six different fishes were collected from drying yards of Sonadia island (a fish processing zone of Bangladesh) that are known sample treated with no insecticides and taken in to account as blank.

\section{A. Proximate biochemical analysis}

Proximate biochemical analysis was done according to the standard methods (Bhuiyan, et. al., 2003).

\section{B. Screening of DDT and Heptachlor}

Apparatus: Mincer fish chopper (Weisser No. $81 \mathrm{~K}$ ), Soxhlet extractor, separatory funnels (500 ml \& $200 \mathrm{ml}$ ), Chromatographic tube (20 mm i.d. $50 \mathrm{~cm}$ long), sample concentrator (Techne dry block DB.3), round bottomed flask (500 ml \& $100 \mathrm{ml}$ ), volumetric flask (50 ml \& $10 \mathrm{ml}$ ), Gas Chromatograph (GC-14B, Shimadzu), syringe(10 $\mu$, Hamilton Co.).

Reagents: Acetone, Diethyl ether, Dimethyl Formamide saturated with petroleum ether, n-hexane, petroleum ether (30$60^{\circ} \mathrm{C}$ ), petroleum ether $\left(30-60^{\circ} \mathrm{C}\right)$ saturated with Dimethyl Formamide, eluting mixture 1 ( petroleum ether + diethyl ether 94:6 v/v), standard solutions , eosin solution (2 mg in $100 \mathrm{ml}$ ), sodium sulphate solution (2 g/ $100 \mathrm{ml} \mathrm{Na} \mathrm{SO}_{4} 10$ $\mathrm{H}_{2} \mathrm{O}$ ), sodium sulphate anhydrous ( heated for at least $2 \mathrm{~h}$ at $550^{\circ} \mathrm{C}$ ), Florisil 60-100 mesh (heated for at least $2 \mathrm{~h}$ at $550^{\circ} \mathrm{C}$, cool \& stored in tightly stoppered container, prior to use heated for at least $5 \mathrm{~h}$ at $130^{\circ} \mathrm{C}$, cool \& add $5 \% \mathrm{w} / \mathrm{w}$ water, shake this mixture for at least $20 \mathrm{~min}$ and stored in a container for at least $10 \mathrm{~h}$ ), cotton wool. All the solvents used for the analysis purchased from MERCK, Germany. DDT \& Heptachlor standards were obtained from Sigma Chemicals.

Sample preparation: All the samples are finely comminuted in a mincer; heating of the samples during comminuting is avoided by briefly chopping several times (Peter and Zeumer, 1987).

Extraction: Triturate a sample of $25 \mathrm{gm}$, with anhydrous Sodium Sulphate to dry, powdery mixture, with the aid of an extraction thimble; extract the mixture exhaustively with Petroleum Ether in Soxhlet apparatus. Concentrate just to dryness the extract solution by a concentrator and dilute to 25 ml with Petroleum Ether saturated with Dimethyl Formamide (Peter and Zeumer, 1987).

Clean up: Clean up was done in two steps- (Peter and Zeumer, 1987).

\section{a) Dimethylformamide-petrolium ether partition:}

Transfer the solution (dissolved in $25 \mathrm{ml}$ Petroleum Ether saturated with Dimethyl Formamide) to $250 \mathrm{ml}$ separatory 
funnel. Rinse the flask with small portion of a previously measured amount of $75 \mathrm{ml}$ Dimethyl Formamide. Then add the remainder of the Dimethyl Formamide to the separatory funnel, and shake vigorously for $1 \mathrm{~min}$. Drain the Dimethyl Formamide phase, and again extract the Petroleum Ether phase with $10 \mathrm{ml}$ Dimethyl Formamide. Transfer the combined Dimethyl Formamide phases to a $500 \mathrm{ml}$ separatory funnel, and add $200 \mathrm{ml}$ sodium sulphate solution. Add a few drops of eosin solution to achieve better recognition of phase separation in the subsequent partition. Then extract successively with a $40 \mathrm{ml}$ portion and three $25 \mathrm{ml}$ potions of petroleum ether for 1 min each time. Wash the combined petroleum ether phases with $10 \mathrm{ml}$ water, dry on sodium sulphate, filter through a cotton wool plug, add $5 \mathrm{ml} \mathrm{n}$-hexane, and concentrate to approx. $5 \mathrm{ml}$.

\section{b) Florisil column chromatography}

About half filled a chromatographic tube with petroleum ether, and sprinkle with $30 \mathrm{~g}$ Florisil in small portions through a funnel with stopcock open, tapping the column in the process. Cover the Florisil with an approx. $2 \mathrm{~cm}$ layer of sodium sulphate. Drain the supernatant solvent after column packing. Pipette the sample solution on to the column. Let the solution percolate to a level of 1-2 mm above the top of the column. Then rinse the flask with small portions of eluting mixture 1 , add the risings to the column, and also let them percolate to a level of 1-2 mm above the top of the column. Next elute the column with the remainder of the total $200 \mathrm{ml}$ amount of eluting mixture 1, at a flow rate of about $5 \mathrm{ml} / \mathrm{min}$. Concentrate the elute near to dry and add $5 \mathrm{ml} \mathrm{n}$ hexane to the elute. Again concentrate the elute to $1 \mathrm{ml}$.

Sample analyses: The DDT \& Heptachlor residues were analyzed by GC-14B, Shimadzu with an electron capture detector (ECD), a manual sampler and GC solution software. A column of $3.1 \mathrm{~m}$ x $3.2 \mathrm{~mm}$; I.D glass spiral; stationary phase silicon OV-17, $5 \%$, aging $300^{\circ} \mathrm{C}$, support chromosorb-W-AW-DMCS, mesh 80/100, $1 \mu \mathrm{m}$ film thickness was used for the chromatographic separation of insecticides. The temperature was fixed for the injector at $250^{\circ} \mathrm{C}$, column at $280^{\circ} \mathrm{C}$, detector at $280^{\circ} \mathrm{C}$. The carrier gas was nitrogen with a $60 \mathrm{ml} / \mathrm{min}$-flow rate. $1.0 \mu \mathrm{l}$ sample was injected for each run and the running time was 25 min. Standards' peak were identified by injecting high concentration of the standard ( $0.5 \mathrm{ppm} \& 0.25 \mathrm{ppm}$ ) and the retention time for DDT $\&$ Heptachlor were determined. Then calibration was done at 3 points ( $25 \mathrm{ppb}, 50 \mathrm{ppb}$ and $100 \mathrm{ppb}$ ) by composite stock standard solution. GC system was calibrated using external standard technique. Individual standard stock solution $(100 \mathrm{mg} / \mathrm{l})$ was prepared by weighing appropriate amounts of active ingredients in a brown bottle with a Teflon-lined screw cap and dissolving the weighed standard in HPLC grade hexane. Stock standard solution was used to prepare primary dilution standards. Appropriate volume of each individual stock solution was taken in a volumetric flask and mixed the solutions to obtain composite stock standard solution.

\section{Analytical quality control}

Gas chromatograph equipped with ECD was checked for linearity. Instrumental limit of detection for GC-ECD was 1.0 $\mu \mathrm{g} / \mathrm{l}$ for organochlorine pesticides. An aliquot of dry fish samples which were collected as blank and treated exactly as a sample including exposure to all glassware, equipments, solvents and reagents used with the sample matrix. No analytic peak was detected in laboratory reagent blank. An aliquot of fortified samples matrix were prepared to which known quantities of the pesticides were added in the laboratory in ppb range. This laboratory fortified matrix was analyzed exactly like the sample. Extraction and clean up were done as mentioned and the recoveries from untreated control samples of dry fish fortified with the analyzed compounds at

Table I. Proximate Biochemical analysis of six dry fishes (the values are in $\% \mathbf{m} / \mathbf{m}$ )

\begin{tabular}{l|c|c|c|c|c}
\hline Name of the dry fish sample & moisture & protein & fat & ash & carbohydrate \\
\hline Bombay duck (Loittya) & 29.14 & 61.22 & 1.87 & 5.09 & 2.68 \\
Ribbon fish (Chhuri) & 25.68 & 64.51 & 1.67 & 5.35 & 2.79 \\
Anchovy (Teilla phasa) & 23.34 & 47.84 & 23.91 & 3.78 & 1.13 \\
Chinese pomfret (Rupchanda) & 43.03 & 46.46 & 4.42 & 3.44 & 2.65 \\
Indian salmon (Lakhua) & 41.02 & 42.50 & 14.33 & 0.21 & 1.94 \\
Croaker (Poa) & 28.50 & 57.91 & 3.73 & 6.44 & 3.42 \\
\hline
\end{tabular}


level of 25 ppb were 96-100\% for Heptachlor and 98-100\% for DDT. Prior to injection of the first sample solution, a standard solution was injected at least three times to check the operating conditions and the constancy of the detector signals. Further linearity of the ECD signal was checked by injecting serial dilutions of DDT \& Heptachlor. A standard solution injected after at least every other sample solution so that any alterations of the gas chromatographic system recognized due to column contamination.

\section{Results and Discussion}

Six samples of dry fishes namely Bombay duck (Loittya), Ribbon fish (Chhuri), Anchovy (Teilla phasa), Croaker (Poa), Chinese pomfret (Rupchanda) and Indian salmon (Lakhua) were analyzed to determine the proximate biochemical composition and to detect DDT and Heptachlor. All of these six samples contained high content of protein ranging minimum $42.50 \%$ in Indian salmon to maximum $64.51 \%$ in Ribbon fish. Dry fish samples also contained relatively higher concentration of ash (mineral) from minimum $0.21 \%$ in Indian salmon to maximum $6.44 \%$ in Croaker. The moisture content was also found high, ranges from 23.34 $\%($ Anchovy) to $43.03 \%$ (Chinese pomfret). The highly priced Chinese pomfret and Indian salmon obtained from the local market contained high moisture (43.03\% and $41.02 \%)$ than the other. The high moisture content is the main cause of infestation by beetles and mites as well as to get more benefit due to more weight of fish. The results obtained from screening of dry fishes for DDT and Heptachlor are alarming for Bangladesh. All of the samples contained invariably health hazard organochlorine insecticides DDT and Heptachlor and the result are shown in Table II and the chromatogram of all the samples (1-6) shown in Fig 1-6.

Table II. DDT \& Heptachlor concentrations in the dry fish samples (the concentrations are in ppb unit)

\begin{tabular}{l|c|c}
\hline \multirow{2}{*}{ Name of the sample } & \multicolumn{2}{|c}{ Organochlorine insecticides } \\
\cline { 2 - 3 } & Heptachlor & DDT \\
\hline Bombay duck (Loittya) & 1.452 & 44.395 \\
Ribbon fish (Chhuri) & 0.778 & 43.158 \\
Anchovy (Teilla phasa) & 18.306 & 19.416 \\
Croaker (Poa) & 14.856 & 16.404 \\
Chinese pomfret (Rupchanda) & 54.753 & 7.849 \\
Indian salmon (Lakhua) & 2.532 & 233.727 \\
\hline
\end{tabular}

From the above study it was found that DDT concentration varied from minimum $7.849 \mathrm{ppb}$ in Chinese pomfret to maximum 233.727 ppb in Indian salmon and Heptachlor concentration varied from minimum $0.778 \mathrm{ppb}$ in Ribbon fish to maximum $54.753 \mathrm{ppb}$ in Chinese pomfret. Generally higher concentrations of organochlorine insecticides were used in more costly dry fishes. Although Indian salmon, a costly dry fish, contained lower concentration of Heptachlor (2.532 ppb) but it contained very high level of DDT (233.727 ppb). Another very costly dry fish, Chinese pomfret, contained lower concentration of DDT (7.849 ppb) but extra ordinarily higher concentration of Heptachlor (54.753 ppb). High concentrations of DDT were found in Bombay duck (44.395 ppb) and Ribbon fish (43.158 ppb) but Heptachlor concentrations were lower (1.452 ppb and $0.778 \mathrm{ppb}$ respectively). DDT contents in Anchovy (19.416 ppb) and Croaker (16.404 $\mathrm{ppb}$ ) were lower than Bombay duck and Ribbon fish but Heptachlor contents of these two fishes (18.306 ppb in Anchovy and 14.856 ppb in Croaker) were high.

The level of concentration of DDT in dry fish is a great concern but more concern is such a dangerous poison is still using in our some popular food items such as dry fish though it is banned in our country (WHO, 2005). DDT is a slow poisoning substance. It can transfer from generation to generation through breast milk (Solomon and Weiss, 2001). It is classified as "moderately toxic" by the US National Toxicological Program and "moderately hazardous" by WHO (WHO, 2005) and EPA classified it as a class B2 probable human carcinogen (US EPA, 1987). Exposed to DDT occupationally have an increased incidence of non-allergic asthma (Brown, 2007), diabetes (Jones et al., 2008), an elevated risk of cancers of the liver and biliary tract (Rogan and Chen, 2005) and increases the risk of breast cancer (Clapp et al., 2008). In areas where it is used for malaria control, infants can be exposed via breast milk in levels that exceed the WHO's acceptable daily intake value for DDT (Bouwman et al., 2006; Ntow et al., 2008). The concentration of Heptachlor in dry fish compare to DDT was found too much less. Heptachlor has been shown to bioaccumulates in fish and cattle. Most of the heptachlor that is swallowed is absorbed into blood. It can pass directly from a mother's blood to an unborn baby through the placenta and is a B2 probable human carcinogen (LDWG, 2007). 


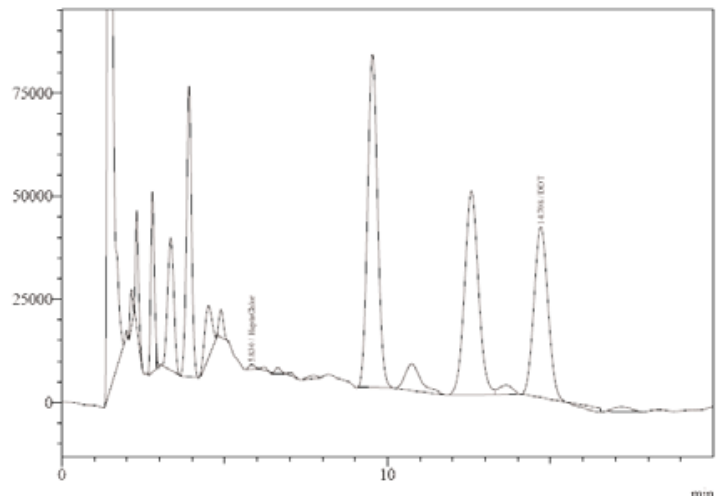

Fig -1: Bombay duck

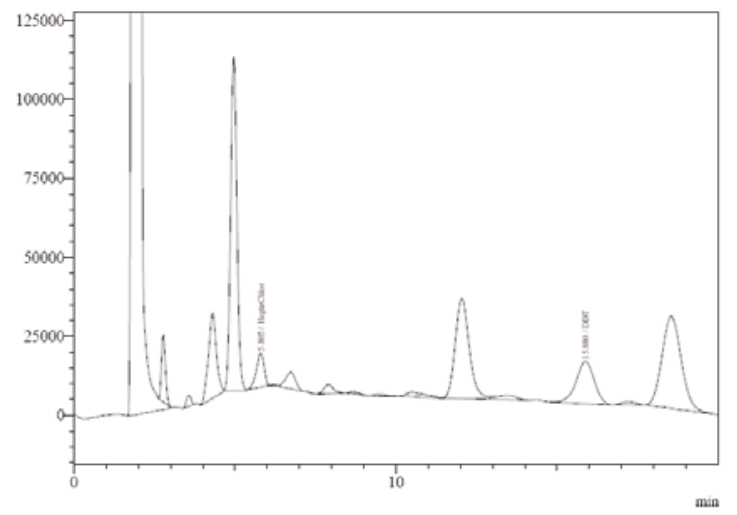

Fig -3: Anchovy

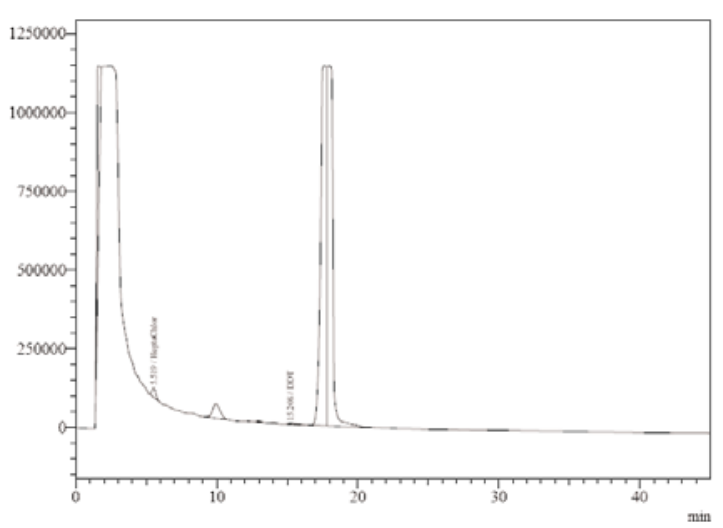

Fig -5: Chinese pomfret

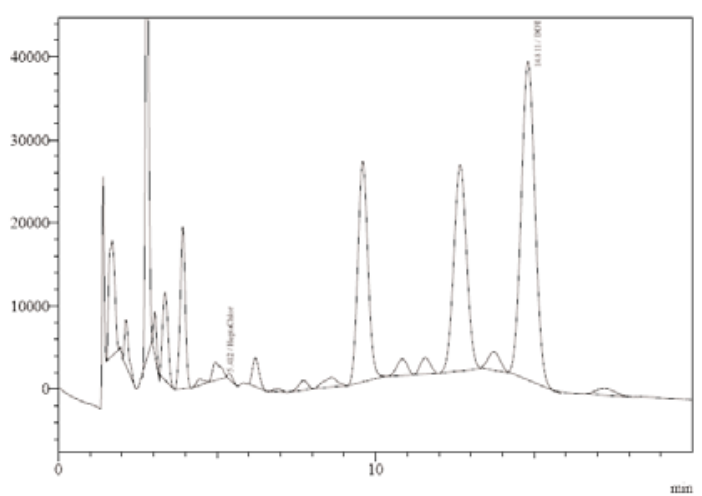

Fig-2: Ribbon fish

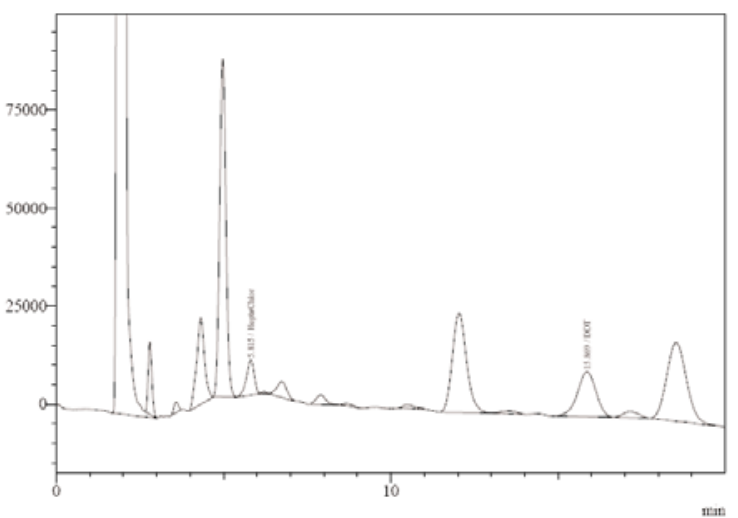

Fig-4: Croaker

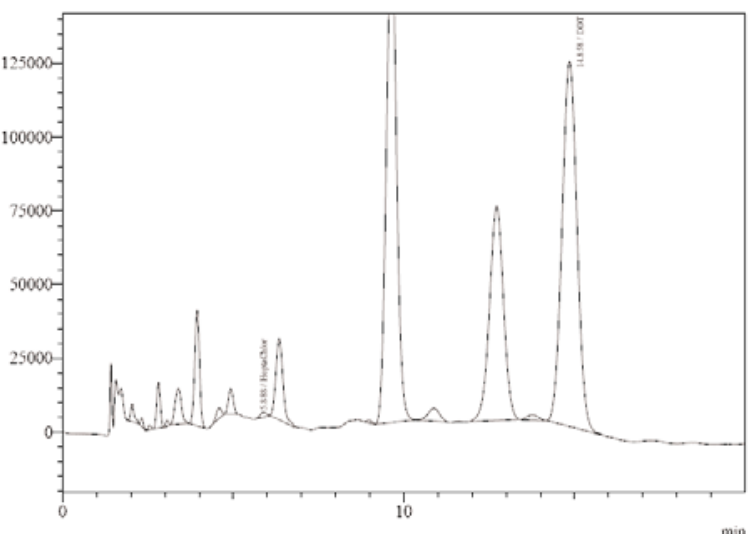

Fig-6: Indian salmon

Fig. (1-6). Showed different chromatograms of DDT and Heptachlor for six samples of dry fishes 
Several study showed that dry fishes contained DDT \& Heptachlor and these insecticides were not removed 100\% by any type of washing, even after washing followed by 10 minutes boiling (Bhuiyan et al., 2008; Bhuiyan et al., 2009). Studies on other food items such as contamination of vegetables with insecticide residues has been reported by several researchers (Madan et al., 1996; Kumari et al., 2002, 2003) and washing was found effective in dislodging the residues as it depends on a number of factors like location of residues, age of residues, water solubility and temperature and type of washing. In earlier studies also, effects of these factors were observed in different vegetables by various researchers (Sarode et al., 1982; Dikshit et al., 1986; Geisman, 1975; Gunther et al., 1963). Some researchers reported 20-89 percent reduction of DDT in potatoes and tomatoes, fenitrothion in okra, parathion in cauliflower and malathion in okra by washing (Farrow et al., 1969; Sarode and Lal, 1982; Elkins, 1989). Boiling was found comparatively more effective than washing in dislodging the residues in vegetables but not completely removed (Kumari, 2008).

From the above study, it is seen that though dry fish is a very good source of protein and mineral, very alarming situation is that health hazard organochlorine insecticides like DDT and Heptachlor are present invariably in all dry fish samples and it also found that the dry fishes contained high moisture means the fishermen do not dry or store the dried fishes properly but they use health hazard substances to protect infestation. As a signatory of the Stockholm Convention, the Government of Bangladesh is required to take action to generate general awareness of consequences of DDT \& Heptachlor through some program, public education campaigns and announcement of harmful rule of these insecticides and make difficult the availability of these insecticides in market either its true pack or false pack. Beside the government the stocker should dry correctly and should pack carefully so that the dry fish can not absorb moisture. The other way of preservation can follow such as freezing, canning and curing.

\section{References}

ATSDR (Agency for Toxic Substances and Disease Registry). (1995) ToxFAQs for DDT, DDE, and DDE. Atlanta, GA: US Department of Health and Human Services, p 39.
Bhuiyan H. R., Chowdhury M. B., Nath K. K., Seal P. and Hossain M. E. (2004) Nutritional studies on three marine fishes of the bay of Bengal. Bangladesh $J$. Sci. Ind. Res. 39 (1-2):101-106.

Bhuiyan H. R., Chowdhury M. B., Nath K. K., Seal P. and Huq M. A. (2003) Studies on biochemical parameters of Cynoglossids in the Kutubdia Channel, Bangladesh. Bangladesh J. Sci. Ind. Res. 38 (1-2): 91-96.

Bhuiyan M. N. H., Bhuiyan H. R, Ahmed K., Dawlatana M., Haque K. M. F., Rahim M. and Bhuiyan M. N. I. (2009) Organochlorine insecticides (DDT and Heptachlor) in dry fish:traditional washing and cooking, effect on dietary intake. Bangladesh $J$ Pharmacol. 4 (1): 46-50.

Bhuiyan M. N. H., Bhuiyan H. R., Rahim M., Ahmed K., Haque K. M. F., Hassan M. T. and Bhuiyan M. N. I. (2008) Screening of organochlorine insecticides (DDT and heptachlor) in dry fish available in Bangladesh. Bangladesh J Pharmacol. 3: 114-120.

Bouwman H., Sereda B. and Meinhardt H. M. (2006) Simultaneous presence of DDT and pyrethroid residues in human breast milk from a malaria endemic area in South Africa. Environ. Pollut. 144: 902-17. http://dx.doi.org/10.1016/j.envpol.2006.02.002

Brown A. J. (2007) Pesticide Exposure Linked to Asthma. Sci Am. 162: 890-97.

Clapp R. W., Jacobs M. M. and Loechler E. L. (2008) Environmental and occupational causes of cancer: new evidence 2005-2007. Rev Environ Health, 23 (1): 1-37.

Dikshit A. K., Handa S. K. and Verma S. (1986) Residues of methamidophos and effect of washing and cooking in cauliflower, cabbage and Indian colza. Indian J Agric Sci. 56: 661-66.

Elkins E. R. (1989) Effect of commercial processing on pesticide residues in selected fruits and vegetables. $J$. Assoc Anal Chem. 72: 533-35. 
Extoxnet (1996) Pesticide Information Profile. Heptachlor.Corvallis, OR: OregonStateUniversity. http://ace.orst.edu/info/extoxnet/pips/heptachl.htm

Farrow R. P., Elkins E. R., Rose W. W., Lamb F. C., Rall J. W. and Mercher W. A. (1969) Canning operations that reduce insecticide level in prepared foods and in solid food wastes. Residue Rev. 29: 73-87.

Geisman J. R. (1975) Reduction of pesticide residues in food crops by processing. Residue Rev. 54: 43-54.

Gunther F. A., Carmen G. E., Blinn R. D. and Barkley J. H. (1963) Persistence of residues of guthion on and in mature lemons and oranges in laboratory processed citrus " Pulp". Cattle Feed. 11: 424-27.

Jensen A. A. and Slorach S. A. (1991) Chemical Contaminants in Human Milk. Boca Raton, FL:CRC Press, Pp 1-8.

Jones O. A. H., Maguire M. L. and Griffin J. L . (2008) Environmental pollution and diabetes: a neglected association, The Lancet. 371: 287-88. http://dx. doi.org/10.1016/S0140-6736(08)60147-6

Kumari B., Kumar R., Madan V. K., Singh, R., Singh, J. and Kathpal, T. S. (2003) Magnitude of pesticidal contamination in winter vegetables from Hisar, Haryana. Environ Monit Assess. 87: 311-18. http://dx.doi.org/10.1023/A:1024869505573 PMid:12952358.

Kumari B., Madan V. K, Kumar R. and Kathpa T. S. (2002) Monitoring of seasonal vegetables for pesticide residues. Environ Monit Assess. 74: 263-70. http://dx.doi.org/10.1023/A:1014248827898 PMid:11944799.

Kumari B. (2008) Effects of household processing on reduction of pesticide residues in vegetables. ARPN $J$. Agric. Biol. Sci. 3: 46-51.

LDWG (Lower Duwamish Waterway Group). (2007) LDW RI: Baseline HHRA Attachment 4. Toxicological Profiles for Chemicals of Potential Concern., p 39.
Madan V. K., Kumari B., Singh R. V., Kumar R. and Kathpal T. S. (1996) Monitoring of pesticide from farmgate samples of vegetables in Haryana. Pestic Res J. 8: 56-60.

Noren K. and Meironyte D. (2000) Certain organochlorine and organobromine contaminants in Swedish human milk in perspective of past 20-30 years. Chemosphere. 40:1111-1123.

Noronha F. (1998) Persistent organic pollutants pervade Asia. Environment News Service. Available: http:// ens.lycos.com/ens/nov98/1998L-11-23-03.html.

Ntow W. J., Tagoe L. M., Drechsel P., Kelderman P., Gijzen H. J. and Nyarko E. (2008) "Accumulation of persistent organochlorine contaminants in milk and serum of farmers from Ghana". Environ. Res. 106: 17-26. http://dx.doi.org/ 10.1016/j.envres. 2007.05. 020 Pmid:17931619

PANNA. (1995) Demise of the Dirty Dozen Chart. San Francisco, CA: Pesticide Action Network North America, p 24.

Peter H. and Zeumer H. (1987) Manual of pesticides residue Analysis, vol.-I, working group analysis. Pesticide commission, Germany, VCH, pp 298-319.

Rogan W. J. and Chen A. (2005) Health risks and benefits of bis (4-chlorophenyl) -1,1,1- trichloroethane (DDT)". Lancet. 366: 763-73. http://dx.doi.org/ 10.1016/ S0140-6736(05)67182-6

Sarode S. V. and Lal R. (1982b) Dissipation of fenitrothion residues on cauliflower. Indian J. Agric. Sci. 52(3):173-76.

Sarode S. V. and Lal R. (1982a) Persistence of residue of fenitrothion in or on okra. Indian J Agric Sci. 52: 135-38.

Solomon G. and Weiss, P. (2001) Healthy Milk, Healthy Baby. New York:Natural Resources Defense Council. Available: http://www.nrdc.org/breastmilk. 
Tannenbaum S. R. (1979) Nutritional and safety aspects of food processing (vol.-6), Marcel Dekker, Inc. New York and Basel, USA, p 300.

UNEP. (2002) United Nations environment program chemicals, Indian Ocean regional report. UNEP Chemicals is a part of UNEP's Technology, Industry and Economics Division, pp 15-67.

US EPA. (1987) Integrated Risk Information System p, p'Dichlorodiphenyltrichloroethane (DDT) (CASRN 50-29-3) __II.A.1. Weight-of-Evidence Characterization. 1987; Retrieved on 2006-04-18. http://www.answers.com/topic/ddt.
WHO (World Health Organization). (2005) The WHO Recommended Classification of Pesticides by Hazard. Brit J Psychiat. 187: 583-84. http://dx.doi.org/10.1192/bjp.187.6.583

WHO. (1988) Heptachlor Health and Safety Guide. Health and Safety Guide 14. Geneva:World Health Organization, p 58.

Received : September 10, 2008;

Accepted : January 18, 2009 